\title{
Analysis of Degraded and Non-Degraded Soils in Irepodun Local Government Area of Kwara State, Nigeria
}

\author{
Samuel Alikwe* \\ Department of Agriculture, Landmark University, Kwara State, Nigeria.
}

*Corresponding Author: Samuel Alikwe, Department of Agriculture, Landmark University, Kwara State, Nigeria.

\begin{abstract}
Comparative analysis of degraded and non-degraded soils in Irepodun local government of kwara state Nigeria was carried out. Soil samples were collected from five different communities (Landmark University \{representing Omu-aran\}, Ipetu, Aran Orin, Oko, and Rore), all in Irepodun Local government of Kwara State, using random sampling. Auger samples were collected from each sampling unit at $0-15 \mathrm{~cm}$. The physical and chemical properties of both degraded and non-degraded soils from these communities namely Omu-Aran, Ipetu, Aran-orin, Rore and Oko were examined. All the samples fell in into the textural class loamy sand with the exception of the degraded soil sample obtained from Aran-Orin. Non-degraded soils in all the study sites have higher values of $N, P, K$ and $C a$ than degraded soils. Nitrogen in non-degraded samples ranges from $(0.1$ to $0.46 \mathrm{cmol} / \mathrm{kg} / \mathrm{N})$, with Ipetu soil (IPND) having the highest and LUND having the lowest, While for degraded soils, the range is between $(0.046-0.09 \mathrm{cmol} / \mathrm{kg} / \mathrm{N})$ for AOD and OKD respectively. CEC is seen lower in most of the non-degraded soils than in the degraded soils. Three of the five degraded soils samples (LUND, AOND and RORND) have higher CEC value, but lower in the remaining two samples. However, there is no correlation seen between $\mathrm{pH}$ and other soil parameters for the non-degraded soils. It was concluded that apart from leaching of basic cations that has led to degradation of soils, farmers also need to be trained on how to save the soil to reduce degradation. Ranging from the addition of soil amendments (organic manure, bio-fertilizers) to the use of integrated soil management practices, strategic steps must be employed to reclaim these soils and boost agricultural production in thearea.
\end{abstract}

Keywords: Agriculture, Analysis, Soil, Degradation.

\section{INTRODUCTION}

Man`s relationship and interactions with his environment has been dynamic. Over the years, man has taken advantage of the natural resources in his environment to meet his needs. Depending on the level of knowledge and civilization, humans have exploited resources within the ecosystem, especially in the modern society of knowledge explosion, which has awakened man`s awareness of the vast resources in his environment. Generally, Man has come to regard his environment as a depot housing his needs and therefore always seeking for ways of extracting the resources within it but always to the sad neglect of the environmental sustenance and consequently the emergence of a number of environmental stresses (Ezeaku et al, 2008). Attempts made by man to extract the environmentalbased resources have always led to one form of soil degradation or the other.

Degraded soils have a health status that does not make them provide the normal goods and services of the particular soil in its ecosystem (FAO, 2016). Soil and land degradation are synonymous, and are both caused by the same factors. About $85 \%$ of the causes of land degradation worldwide are due to soil erosion by wind and water. Hence soil and land degradation are often used interchangeably. According to (FAO, 2009), the world's current population is about 7 billion sand it is projected to be 9.1 billion by year $2050,34 \%$ higher than the current population. Nearly all the increase will be from the developing world. Agricultural production is growing at a slower rate of about FAO (2004) revealed that $99.7 \%$ of human food (calories) comes from the land, while less than $03 . \%$ comes from oceans and other aquatic ecosystems. It becomes very clear that paying quality attention to the status of our soils and maintaining its quality and fertility is the major way to combat food insecurity globally. Erosion has been identified as one of the major causes of soil degradation globally. 
Farmers in Irepodun Local government area of Kwara State have been experiencing low yield in production, largely because of the impact of degradation on the soils in the area. This study is therefore aimed at studying the relationship between the properties (physical and chemical) of both degraded and non-degraded soils, and how these properties affects crop performance.

\section{Materials AND Methodology}

\subsection{Sources of Soil Sample}

Soil samples were collected from five different communities (Landmark University \{representing Omu-aran\}, Ipetu, Aran Orin, Oko, and Rore), all in Irepodun Local government of Kwara State, using random sampling. Auger samples were collected from each sampling unit at $0-15 \mathrm{~cm}$. Samples were collected from exposed and washed areas to represent degraded soil while non- degraded soils were obtained from rich and fertile farmlands. In each community, both degraded and non-degraded samples were collected. The soil samples were transported to the laboratory in well-labeled polyethylene bags. The samples were then air-dried and passed through a $2 \mathrm{~mm}$ except for sample used to determine organic matter/carbon in which $5 \mathrm{~mm}$ sieve was used in separating the gravel from the soil. The physicochemical analyses of the samples were the carried out.

\subsection{Physicochemical Analyses}

Particle size analysis of the soil was by the hydrometer method of Bouyoucos (1951). The pH was determined using the $\mathrm{pH}$ meter glass electrode. The wet oxidation method of walkley and Black (1934) was used in the determination of soil organic carbon. The organic matter content was then calculated by multiplication with a correcting factor (1.724). The soil nitrogen was determined using the automatic Kjeldahl digestion method (Bremner, 1965), while exchangeable acidity was known using titration method. The cation exchange capacity (CEC) and exchangeable bases (K, Ca, Na, and $\mathrm{Mg}$ ) were determined by ammonium acetate method of Chapman (1965). Also the Bray-1 method was used in the determination of available phosphorus (Murphy and Riley. 1962). The determination of micronutrients was carried out using the atomic absorption spectrophotometer.

\section{RESULT AND DISCUSSION}

Figure 1 shows the chemical properties of degraded and non-degraded soils. It reveals that nondegraded soils in most of the study sites appeared to be slightly acidic than degraded soils. The $\mathrm{pH}$ of non-degraded soils ranges between 5.5 and 6.9, while that of most degraded soils ranges from slightly acidic to basic, with Rore soil having the highest value of 6.9 for the non-degraded sample and 7.3for the degraded sample. This shows that degradation have negative impact on soil $\mathrm{pH}$, as leaching occurs and the top soils are been washed away, and essential nutrients are also carried away.

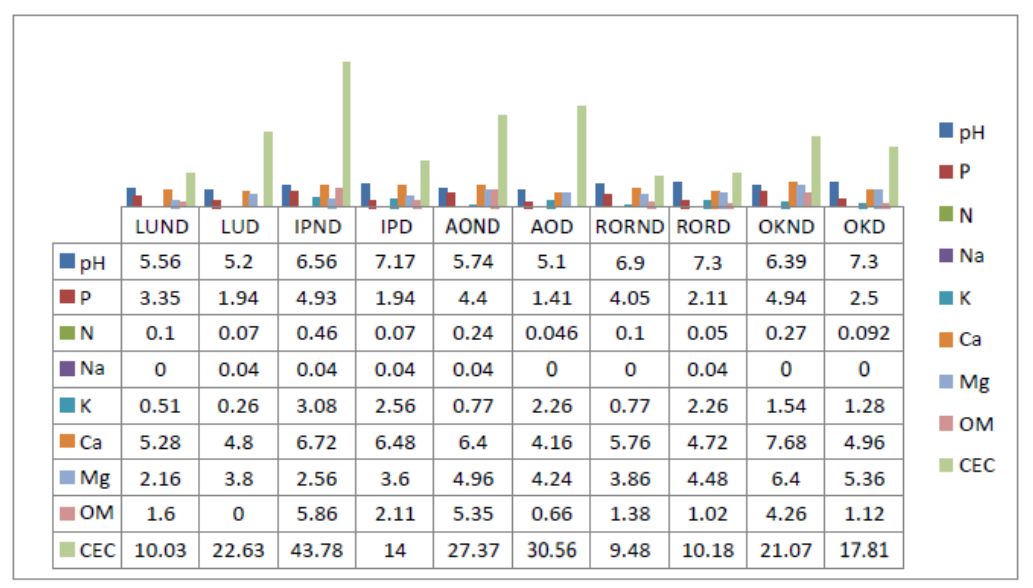

Figure1. Chemical properties of degraded and non-degraded soils.

LUND (Landmark University Non-Degraded soils), LUD (Landmark University degraded soil), IPND (Ipetu Non-Degraded soil), IPD (Ipetu Degraded soil), AOND (Aran-Orin Non-degraded soil), AOD ( Aran-Orin Degraded soil), RORND (Roren On-Degraded soil), RORD (Rore Degraded soil), OKND (Oko Non-degraded soil), OKD (Oko Degraded soil).

Ph (Soil pH), P (Phosphorus), N (Nitrogen), Na (Sodium), K (Potassium), Ca (Calcium), Mg (Magnesium), OM (Organic matter), CEC (Cation exchange capacity). 
Analysis of Degraded and Non-Degraded Soils in Irepodun Local Government Area of Kwara State, Nigeria

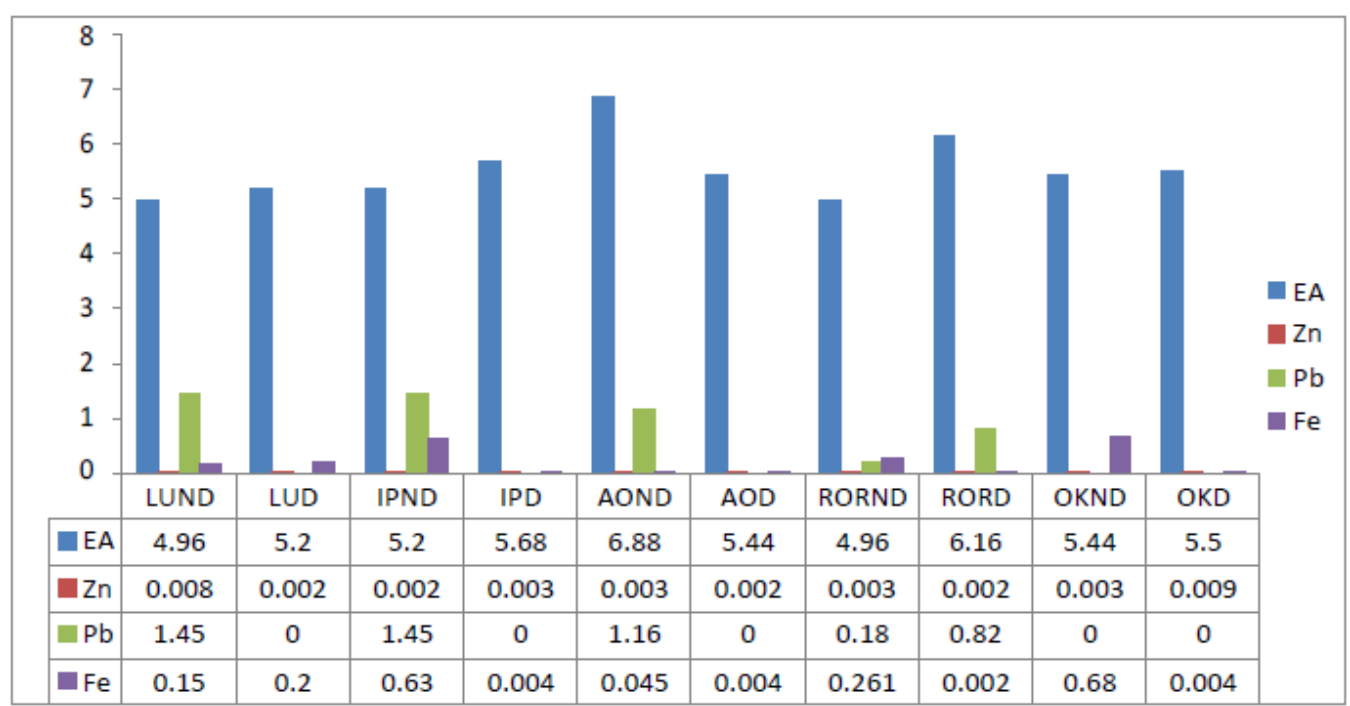

Figure2. Chemical properties of degraded and non-degraded soils.

EA (Exchangeable acidity), Zn (Zinc), Pb (Lead), Fe (Iron),

Table1. Correlations Coefficient of the chemical characteristics of Non-degraded soils

\begin{tabular}{|c|c|c|c|c|c|c|c|c|c|c|c|c|c|c|}
\hline & $\mathrm{pH}$ & $\mathrm{N}$ & $\mathrm{P}$ & $\mathrm{Na}$ & K & $\mathrm{Ca}$ & $\mathrm{Mg}$ & $\mathrm{Zn}$ & $\mathrm{Pb}$ & $\mathrm{Fe}$ & CEC & EA & $\mathrm{OC}$ & $\mathrm{OM}$ \\
\hline \multirow[t]{2}{*}{$\mathrm{pH}$} & 1 & .228 & .505 & -.129 & .448 & .304 & .280 & -.601 & -.592 & .569 & .133 & -.433 & -.030 & -.031 \\
\hline & & .713 & .386 & .836 & .450 & .619 & .649 & .283 & .293 & .317 & .831 & .466 & .962 & .960 \\
\hline \multirow[t]{2}{*}{$\mathrm{N}$} & .228 & 1 & .817 & .712 & $937^{*}$ & .644 & .023 & -.296 & .281 & .662 & $74^{* *}$ & .172 & $893^{*}$ & $893^{*}$ \\
\hline & .713 & & .092 & .177 & .019 & .240 & .970 & .628 & .647 & .224 & .005 & .782 & .041 & .041 \\
\hline \multirow[t]{2}{*}{$\mathrm{P}$} & .505 & .817 & 1 & 451 & .748 & $909^{*}$ & .553 & -.737 & -.297 & .746 & .735 & .257 & .793 & .793 \\
\hline & .386 & .092 & & 445 & .146 & .032 & .334 & .156 & .628 & .148 & .157 & .676 & .110 & .110 \\
\hline \multirow[t]{2}{*}{$\mathrm{Na}$} & -.129 & .712 & .451 & 1 & .514 & .190 & -.284 & -.264 & .592 & -.045 & .849 & .627 & .836 & .836 \\
\hline & .836 & .177 & .445 & & .376 & .759 & .644 & .668 & .293 & .943 & .069 & .257 & .078 & .078 \\
\hline \multirow[t]{2}{*}{$\mathrm{K}$} & .448 & $937^{*}$ & .748 & .514 & 1 & .544 & -.061 & -.213 & .196 & .786 & .875 & -.168 & .684 & .683 \\
\hline & .450 & .019 & .146 & .376 & & .343 & .922 & .731 & .751 & .115 & .052 & .788 & .203 & .204 \\
\hline \multirow[t]{2}{*}{$\mathrm{Ca}$} & .304 & .644 & $909^{*}$ & .190 & .544 & 1 & .772 & -.626 & -.438 & .755 & .514 & .262 & .680 & .680 \\
\hline & .619 & .240 & .032 & .759 & .343 & & .126 & .258 & .460 & .140 & .375 & .670 & .207 & .207 \\
\hline \multirow[t]{2}{*}{$\mathrm{Mg}$} & .280 & .023 & .553 & -.284 & -.061 & .772 & 1 & -.676 & -.836 & .408 & -.111 & .252 & .173 & .174 \\
\hline & .649 & .970 & .334 & .644 & .922 & .126 & & .210 & .078 & .495 & .859 & .682 & .780 & .780 \\
\hline \multirow[t]{2}{*}{$\mathrm{Zn}$} & -.601 & -.296 & -.737 & -.264 & -.213 & -.626 & -.676 & 1 & .616 & -.273 & -.276 & -.431 & -.428 & -.428 \\
\hline & .283 & .628 & .156 & .668 & .731 & .258 & .210 & & .268 & .656 & .653 & .468 & .472 & .472 \\
\hline \multirow[t]{2}{*}{$\mathrm{Pb}$} & -.592 & .281 & -.297 & .592 & .196 & -.438 & -.836 & .616 & 1 & -.330 & .423 & .149 & .275 & .275 \\
\hline & .293 & .647 & .628 & .293 & .751 & .460 & .078 & .268 & & .588 & .478 & .811 & .654 & .654 \\
\hline \multirow[t]{2}{*}{$\mathrm{Fe}$} & .569 & .662 & .746 & -.045 & .786 & .755 & .408 & -.273 & -.330 & 1 & .480 & -.394 & .388 & .387 \\
\hline & .317 & .224 & .148 & .943 & .115 & .140 & .495 & .656 & .588 & & .413 & .512 & .519 & .520 \\
\hline \multirow[t]{2}{*}{ CEC } & .133 & $.974^{* *}$ & .735 & .849 & .875 & .514 & -.111 & -.276 & .423 & .480 & 1 & .297 & $.919^{*}$ & $.918^{*}$ \\
\hline & .831 & .005 & .157 & .069 & .052 & .375 & .859 & .653 & .478 & .413 & & .627 & .027 & .028 \\
\hline \multirow[t]{2}{*}{ EA } & -.433 & .172 & .257 & .627 & -.168 & .262 & .252 & -.431 & .149 & -.394 & .297 & 1 & .592 & .593 \\
\hline & .466 & .782 & .676 & .257 & .788 & .670 & .682 & .468 & .811 & .512 & .627 & & .293 & .292 \\
\hline \multirow[t]{2}{*}{$\mathrm{OC}$} & -.030 & & .793 & .836 & .684 & .680 & .173 & -.428 & .275 & .388 & $.919^{*}$ & .592 & 1 & $1.000^{* *}$ \\
\hline & .962 & .041 & .110 & .078 & .203 & .207 & .780 & .472 & .654 & .519 & .027 & .293 & & .000 \\
\hline \multirow[t]{2}{*}{$\mathrm{OM}$} & -.031 & $.893^{*}$ & .793 & .836 & .683 & .680 & .174 & -.428 & .275 & .387 & $918^{*}$ & .593 & $1.000^{* *}$ & 1 \\
\hline & .960 & .041 & .110 & .078 & .204 & .207 & .780 & .472 & .654 & .520 & .028 & .292 & .000 & \\
\hline
\end{tabular}

*. Correlation is significant at the 0.05 level (2-tailed).

**. Correlation is significant at the 0.01 level (2-tailed). 
Analysis of Degraded and Non-Degraded Soils in Irepodun Local Government Area of Kwara State, Nigeria

Table2. Correlations Coefficient of the chemical characteristics of degraded soils

\begin{tabular}{|c|c|c|c|c|c|c|c|c|c|c|c|c|c|c|}
\hline & $\mathrm{pH}$ & $\mathrm{N}$ & $\mathrm{P}$ & $\mathrm{Na}$ & $\mathrm{K}$ & $\mathrm{Ca}$ & $\mathrm{Mg}$ & $\mathrm{Zn}$ & $\mathrm{Pb}$ & $\mathrm{Fe}$ & CEC & EA & $\mathrm{OC}$ & OM \\
\hline \multirow[t]{2}{*}{$\mathrm{PH}$} & 1 & .482 & .747 & .130 & .564 & .544 & .394 & .411 & .429 & -.587 & \multirow{2}{*}{$\begin{array}{c}-.881^{*} \\
.049\end{array}$} & .701 & .529 & .528 \\
\hline & & .411 & .147 & .835 & .322 & .343 & .512 & .492 & .471 & .298 & & .187 & .359 & .361 \\
\hline \multirow[t]{2}{*}{$\mathrm{N}$} & .482 & 1 & .804 & -.187 & .527 & .413 & .474 & $18^{*}$ & -.411 & .025 & -.279 & -.270 & .384 & .382 \\
\hline & .411 & & .101 & .763 & .361 & .490 & .420 & $\begin{array}{l}.948 \\
.014\end{array}$ & .492 & .968 & .649 & .661 & .524 & .526 \\
\hline \multirow[t]{2}{*}{$\mathrm{P}$} & .747 & .804 & 1 & .079 & .274 & .279 & .593 & .758 & .206 & -.051 & -.685 & .238 & .257 & .254 \\
\hline & .147 & .101 & & .900 & .656 & .650 & .292 & . 138 & .740 & .935 & .202 & .700 & .676 & .680 \\
\hline \multirow[t]{2}{*}{$\mathrm{Na}$} & .130 & -.187 & .079 & 1 & .113 & .467 & $\begin{array}{l}-.674 \\
\end{array}$ & $\begin{array}{l}-.460 \\
\end{array}$ & .382 & .457 & -.563 & .275 & .493 & .492 \\
\hline & .835 & .763 & .900 & & .856 & .428 & .212 & .435 & .525 & .439 & .323 & .654 & .398 & .400 \\
\hline \multirow[t]{2}{*}{$\mathrm{K}$} & .564 & .527 & .274 & .113 & 1 & $931^{*}$ & -.183 & .342 & -.364 & -.366 & -.400 & .067 & $920^{*}$ & $920^{*}$ \\
\hline & .322 & .361 & .656 & .856 & & $\begin{array}{l}.931 \\
.021\end{array}$ & .768 & .574 & .547 & .544 & .504 & .915 & .9200 & $\begin{array}{l}.920 \\
.027\end{array}$ \\
\hline \multirow[t]{2}{*}{$\mathrm{Ca}$} & .544 & .413 & .279 & .467 & $931^{\circ}$ & 1 & -.409 & .146 & -.196 & -.144 & -.557 & .145 & $999^{* *}$ & $999^{* * *}$ \\
\hline & .343 & .490 & .650 & .428 & $\begin{array}{l}.931 \\
.021\end{array}$ & & .494 & .814 & .752 & .817 & .329 & .816 & .000 & .000 \\
\hline \multirow[t]{2}{*}{$\mathrm{Mg}$} & .394 & .474 & .593 & -.674 & -.183 & -.409 & 1 & .702 & .150 & -.402 & -.085 & .150 & -.439 & -.440 \\
\hline & .512 & .420 & .292 & .212 & .768 & .494 & & .186 & .810 & .502 & .892 & .810 & .460 & .459 \\
\hline \multirow[t]{2}{*}{$\mathrm{Zn}$} & .411 & $948^{*}$ & .758 & -.460 & .342 & .146 & .702 & 1 & -.391 & -.090 & -.118 & -.279 & .112 & .111 \\
\hline & .492 & .014 & .138 & .435 & .574 & .814 & .186 & & .515 & .885 & .850 & .650 & .858 & .859 \\
\hline \multirow[t]{2}{*}{$\mathrm{Pb}$} & .429 & -.411 & .206 & .382 & -.364 & -.196 & .150 & -.391 & 1 & -.250 & -.625 & .878 & -.182 & -.184 \\
\hline & .471 & .492 & .740 & .525 & .547 & .752 & .810 & .515 & & .685 & .259 & .050 & .770 & .768 \\
\hline \multirow[t]{2}{*}{$\mathrm{Fe}$} & -.587 & .025 & -.051 & .457 & -.366 & -.144 & -.402 & -.090 & -.250 & 1 & .254 & -.617 & -.130 & -.132 \\
\hline & .298 & .968 & .935 & .439 & .544 & .817 & .502 & .885 & .685 & & .681 & .268 & .834 & .833 \\
\hline \multirow[t]{2}{*}{ CEC } & $881^{*}$ & -.279 & -.685 & -.563 & -.400 & -.557 & -.085 & -.118 & -.625 & .254 & 1 & -.749 & -.558 & -.556 \\
\hline & $\begin{array}{r}-.881 \\
.049\end{array}$ & .649 & .202 & .323 & .504 & .329 & .892 & .850 & .259 & .681 & & .145 & .328 & .331 \\
\hline \multirow[t]{2}{*}{ EA } & .701 & -.270 & .238 & .275 & .067 & .145 & .150 & -.279 & .878 & -.617 & -.749 & 1 & .152 & .151 \\
\hline & .187 & .661 & .700 & .654 & .915 & .816 & .810 & .650 & .050 & .268 & .145 & & .807 & .808 \\
\hline \multirow[t]{2}{*}{$\mathrm{OC}$} & .529 & .384 & .257 & .493 & & & -.439 & .112 & -.182 & -.130 & -.558 & .152 & 1 & $000^{* *}$ \\
\hline & .359 & .524 & .676 & .398 & .027 & .000 & .460 & .858 & .770 & .834 & .328 & .807 & & .000 \\
\hline \multirow[t]{2}{*}{$\mathrm{OM}$} & .528 & .382 & .254 & .492 & & & -.440 & .111 & -.184 & -.132 & -.556 & .151 & $1000^{* *}$ & 1 \\
\hline & .361 & .526 & .680 & .400 & .027 & .000 & .459 & .859 & .768 & .833 & .331 & .808 & .000 & \\
\hline
\end{tabular}

*. Correlation is significant at the 0.05 level (2-tailed).

**. Correlation is significant at the 0.01 level (2-tailed).

Table3. Textural class Analysis Result (Particle Size Distribution)

\begin{tabular}{|c|c|c|c|c|}
\hline SOIL & \% clay & \% silt & \% sand & \% sand \\
\hline LUND & 6.880 & 11.00 & 82.12 & 82.12 \\
\hline LUD & 17.88 & 11.00 & 71.12 & 71.12 \\
\hline AOND & 8.880 & 17.00 & 74.12 & 57.12 \\
\hline AOD & 30.88 & 12.00 & 57.12 & 81.12 \\
\hline IPND & 3.880 & 15.00 & 81.12 & 86.12 \\
\hline IPD & 8.880 & 5.00 & 86.12 & 83.12 \\
\hline RORND & 9.880 & 7.00 & 83.12 & 88.12 \\
\hline RORD & 5.880 & 6.00 & 88.12 & 74.12 \\
\hline OKND & 4.880 & 12.00 & 83.12 & 74.12 \\
\hline OKND & 16.88 & 9.000 & 74.12 & \\
\hline
\end{tabular}

- All the samples fell into the textural class loamy sand with the exception of the degraded soil sample obtained from Aran-Orin. Since AOD is a degraded soil, there is possibility that the high clay content may be as a result of accumulation of washed clay soil particles by erosion.

\section{DISCUSSION}

Non-degraded soils in all the study sites have higher values of $\mathrm{N}, \mathrm{P}, \mathrm{K}$ and $\mathrm{Ca}$ than degraded soils. Nitrogen in non-degraded samples ranges from $(0.1$ to $0.46 \mathrm{cmol} / \mathrm{kg} / \mathrm{N})$, with Ipetu soil (IPND) having the highest and LUND having the lowest. While for degraded soils, the range is between (0.046$0.09 \mathrm{cmol} / \mathrm{kg} / \mathrm{N}$ ) for AOD and OKD respectively. This work is in-line with (Natrajan et al., 2010), who noted that the concentrations of nutrients in eroded soil are twice less those in the soil from which they are derived, owing to selective removal of fine particles. Assuming that typical topsoil 
Analysis of Degraded and Non-Degraded Soils in Irepodun Local Government Area of Kwara State, Nigeria

contains $0.2 \%$ nitrogen, erosion of $20 \mathrm{t}$ of soil will remove $80 \mathrm{~kg}$ of nitrogen, together with other nutrients. This is equivalent to carrying several bags of fertilizer away from each field every year. There is a further effect from loss of organic matter by erosion, causing degradation of soil physical conditions.

Phosphorus in non-degraded soils appeared to be much higher than that of the degraded soils with Ipetu soil (IPND) and Oko soil (OKND) having the highest of 4.932ppm as the highest and Landmark soil (LUND) with the lowest of 3.35ppm. The phosphorus content of degraded soils is in order OKD $>$ RORD > (IPD, LUD) > AOD with OKD having a phosphorus content of 2.46 as the highest and AOD having a phosphorus content of 1.41 as the least. (Ichikogu, 2012) noted that the concentration of total nitrogen and available phosphorus in the topsoil are higher than the subsoil. Torbert et al (2002) showed that soil phosphorus availability is greatest at the soil surface and decreases with depth.

Calcium and potassium followed the same trend as the other macro nutrients mentioned above. Nondegraded soils have higher level of calcium than degraded soils. Non-degraded soils have calcium with the highest value of $(7.68 \mathrm{cmol} / \mathrm{kg} / \mathrm{ca}$ OKND) and lowest of $(5.28 \mathrm{cmol} / \mathrm{kg} / \mathrm{ca} \mathrm{LUND})$. While Ca in degraded soils was low compared to their non-degraded counterparts, with the highest value of $(4.96 \mathrm{cmol} / \mathrm{kg} / \mathrm{ca}$ for Oko soil and a lowest value of $4.16 \mathrm{cmol} / \mathrm{kg} / \mathrm{ca}$ for Aran-Orin soil. Non-degraded soils have a potassium range between 3.08 and $0.51 \mathrm{cmol} / \mathrm{kg} / \mathrm{K}$ (for IPND and LUND respectively), while degraded soils have a potassium range between $(0.25$ and $2.56 \mathrm{cmol} / \mathrm{kg} / \mathrm{K})$, with LUD, AOD, RORD having the lowest and IPD having the high of 2.56 .

The fact that the top soils of the non-degraded soils are still intact and houses the nutrients explains the high level of the major macronutrients in the non-degraded soils than in the degraded soil samples. As degradation sets in and washes away the topsoil, this leads to the reduction in the amount of nutrients in the soil. Eroded soil carries away vital plant nutrients such as nitrogen, phosphorus, potassium, and calcium. Typically, the eroded soil contains about three times more nutrients per unit weight than are left in the remaining soil. Fertile soils typically contain 100 tons of organic matter per hectare (4\% to $5 \%$ of total topsoil weight).About $95 \%$ of the soil nitrogen and 25 to $50 \%$ of the phosphorus is contained in the soil organic matter. Because most soil organic matter is found close to the soil surface as decaying leaves and stems, erosion significantly reduces the soil organic matter (Sundquist, B. 2010, Pimentel, D.et al., .2005).

Degradation, majorly by erosion accounts for the low level of major elements in the degraded soil samples. Senjobi1 and Ogunkunle (2011) also attributed low level of Calcium and potassium in some soils to leaching of nutrients and weathering, consequently leading to the inherent low fertility status of the soil.

For magnesium, the result obtained from this research shows a slight deviation from the normal trend of the other macro nutrients. The magnesium content, was higher in two of the non- degraded soil samples (OKND and AOND), but lower in the remaining three other samples. This may be due to intense cultivation of the soils (Senjobil and Ogunkunle, 2011).

Non degraded soils samples were however seen to have higher values in terms of organic carbon and organic matter with IPND having the highest value (3.4 OC) and RORND having the least of $(0.8)$. The degraded soil samples however had lower values in terms of organic carbon with IPD having a high of 1.22 and AOD having a low of 0.38. This is acceptable as most of the non- degraded soils are not exposed, so most of the organic residues are deposited on the soil surface, as against the situation with the degraded soils where most of the topsoil are washed away. More severely eroded areas lost more soil and soil organic matter, therefore less organic matter and nutrients were left available for plant nutrition on the newly exposed eroded arable topsoil (Senjobi1 and Ogunkunle, 2011).

CEC is seen lower in most of the non-degraded soils than in the degraded soils. Three of the five degraded soils samples (LUND, AOND and RORND) have higher CEC value, but lower in the remaining two samples. The fact that some of the non-degraded soil samples have higher level of CEC than the non-degraded may be because organic matter and clay content makes up the CEC. The degraded soils have higher clay content than the non-degraded soil samples. Perm culture (2016) explains that the primary factor determining CEC among other things is the clay and organic matter 
Analysis of Degraded and Non-Degraded Soils in Irepodun Local Government Area of Kwara State, Nigeria

content of the soil. Higher quantities of clay and organic matter beget higher CEC. The two nondegraded soil samples with high values of CEC may as well be as a result of the high organic carbon content.

(Clain Jones and Jeff Jacobsen 2001) also noted that CEC is higher in soils with high amounts of clay and organic matter, and is lower in acid soils.

\subsection{Comparative Analysis of the Chemical Properties of Degraded and Non- Degraded Soils Using Correlation Relationship}

From the correlation result of both the degraded and non-degraded soil, the following were observed:

For degraded soils, the $\mathrm{pH}$ has a negative correlation with CEC at 0.05 significant levels. It is evident that any effort to increase the $\mathrm{pH}$ of the degraded soils will have a negative effect on the CEC. However, there is no correlation seen between $\mathrm{pH}$ and other soil parameters for the non- degraded soils. Soil pH is a less obvious factor affecting CEC (Camberato, 2001), as observed for the nondegraded soil samples.

In the non-degraded soil samples, nitrogen showed a positive correlation with potassium and organic carbon both at 0.05 significant levels and a strong correlation with CEC at 0.01 significant levels. For the degraded soil samples however, nitrogen showed a positive correlation with only $\mathrm{Zn}$ at 0.05 at significant level. Abad et, al 2014, however reported a negative correlation between potassium and nitrogen as against what was noted for the non-degraded soil samples. Phosphorus showed a positive correlation with calcium for the non-degraded soil samples. The correlation relationship between calcium and phosphorus indicates that the presence of phosphorus increases the availability of calcium.

Potassium showed a positive significant correlation relationship with $\mathrm{Ca}$ and organic carbon, both at 0.05 significant levels for the degraded soils. However, potassium only showed a significant relationship with only sodium at 0.05 level for the non-degraded soils. A positive correlation was observed between calcium and phosphorus at 0.05 level for the non-degraded soils. Calcium showed a positive significant correlation relationship with potassium and organic carbon at 0.05 and 0.01 level of significance. Magnesium, Zinc, Lead and Iron showed a non- significant correlation relationship with other parameters studied, for the non-degraded soils. The same applies to the degraded soils, except for Zinc that has a significant positive correlation relationship with nitrogen.

Cation exchange capacity showed a positive significant correlation relationship with nitrogen and organic matter 0.01and 0.05 significant level respectively for the non-degraded soils. A positive significant correlation relationship was seen between organic matter and nitrogen, organic and CEC for the non-degraded soils, both at 0.05 level of significance. This result is in line with Senjobi, 2007; Senjobi et al., 2010. Who noted organic matter to have a positive influence on the CEC, base saturation, structure, $\mathrm{pH}$, buffering capacity, soil colour, and water holding capacity.

Organic matter however showed a positive significant correlation relationship with potassium and calcium, both at 0.05 and 0.01 level of significance respectively for the degraded soils. (Chauhan 2001) also reported a positive relationship between organic matter and Potassium, as seen in the result of the degraded soils.

The interrelationships between nutrients in the soil and plant system are quite complicated and interdependent. More research will need to be done on the molecular levels to elucidate the actual relationships if possible.

\section{CONCLUSION}

From the analysis carried out, it was observed that while most of the non-degraded soils in the study sites are rich in nutrients and are therefore good for agricultural productivity, the degraded soils, on a large scale lack essential nutrients required for plant growth. This is due to the distortion that has occurred on the soil, majorly by erosion, leading to the loss of essential elements. Erosion results to leaching of basic cations which causes ionic imbalance in the soil. The addition of soil amendments (organic manure, bio-fertilizers) and the use of integrated soil management practices can be employed 
Analysis of Degraded and Non-Degraded Soils in Irepodun Local Government Area of Kwara State, Nigeria

as strategies to reclaim these soils. It is also important that the government put in place modalities to cushion the effect of some anthropogenic activities that fosters erosion like poor management, construction activities, deforestation, continuous cropping etc.; this will help ensure that more soils are not exposed to degradation. Apart from leaching of basic cations that has led to degradation of soils, farmers also need to be trained on how to save the soil to reduce degradation. Ranging from the addition of soil amendments (organic manure, bio-fertilizers) to the use of integrated soil management practices, strategic steps must be employed to reclaim these soils and boost agricultural production in the area. It is important to understand that paying quality attention to the status of the soils in the area and maintaining its quality and fertility will go a long way in combating food insecurity in Irepodun Local Government Area of Kwara State.

\section{REFERENCES}

[1] Ezeaku, P. I. and A. Davidson, 2008. Analytical situations of land degradation and sustainable management strategies in Africa. J. Agri. Soc. Sci., 4: 42-52

[2] FAO Soil Portal, Soil Degradation. (2016, February 12). Retrieved from http://www.fao.org/soilsportal/soil-degradation-restoration/en/

[3] FAO (2009). How to Feed the World in 2050, FAO Rome.

[4] FAO. FAO Food Balance Sheets.FAOSTAT, Food and Agriculture Organization of the United Nations, 2004.First printed in South Carolina Turfgrasss Foundation News, October-December, 2001.

[5] Bouyoucos GH (1951). A Reclamation of the Hydrometer for Making Mechanical Analy. Soil Agro. J. 43:434-438. Carbon in soils: Effect of variations in digestion conditions and of inorganic soil constituents. Soil Sci. 63:251-263.

[6] Walkley, A. and I.A. Black. 1934. An examination of the Degtjareff method for determining organic

[7] Bremner, J. (1965) Inorganic Forms of Nitrogen. Methods of Soil Analysis.Part 2. Chemical and Microbiological Properties, 1179-1237.

[8] Chapman, H.D., "Cation-exchange Capacity,"pp. 891-900, in C.A. Black (ed.), Method of Soil Analysis, Part 2: Chemical and Microbiological Properties, Am. Soc. Agron., Madison, Wisconsin (1965).

[9] Murphy, J. and J. P. Riley. 1962. A modified single solution method for the determination of phosphate in natural waters. Anal.Chim. Acta 27: 31-36

[10] A. Natarajan*, RajendraHegde, L.G. K. Naidu, A. Raizada, R. N. Adhikari, S. L. Patil, K. Rajan and DipakSarkar 2010. Soil and plant nutrient loss during the recent floods in North Karnataka: Implications and ameliorative measures. Current Science. 99(10): 1333-1340.

[11] Ichikogu, V.I. 2012. Total nitrogen and available phosphorus dynamics insoils regenerating from degraded abandoned rubber plantation in orogunarea of the rainforest zone of southern Nigeria. Abstract.

[12] Tobert, H.A, T.C Daniel, and J.L Lemunyon (2002): Relationship of soil test phosphorus and sampling depth of run-off phosphorus in calcerous and non-calcerous soils. J. environ. Qual. 31:1380-1382

[13] Sundquist, B. 2010. Food Supply from Soil. Topsoil Loss and Degradation-Causes, Effects and Implications, chapter 9.

[14] David Pimentel, Paul Hepperly, James Hanson, David Douds and Rita Seidel, 2005. Environmental, energetic and economic comparisons of organic and conventional farming systems.BioScience, 573-582.

[15] Senjobi B.A, A. O. Ogunkunle (2011). Effect of different land use types and their implications on land degradation and productivity in Ogun State, Nigeria.

[16] Permaculture, 2016. The Soils Cation Exchange Capacity and its Effect on Soil Fertility.Retrived from https://permaculturenews.org/2016/10/19/soils-cation-exchange-capacity-effect-soil-fertility/

[17] Clain Jones and Jeff Jacobsen 2001. Nutrient Management Module No. 2, a self-study course from the MSU Extension Service Continuing Education Series. Plant Nutrition and Soil, MSU Extension Service Fertility. Conference on land degradation and desertification New Delhi, India: Oxford press.

[18] James J. Camberato (2001). Clemson University, Crop and Soil Environmental Science

[19] Abad et, al 2014. Assessment the effects of land use changes on soil physicochemical properties in Jafarabad of Golestan province, Iran. Bulletin of Environment, Pharmacology and Life Sciences Bull. Env.Pharmacol. Life Sci., Vol 3 Spl Issue III 2014: 296-300 @2014 Academy for Environment and Life Sciences, India Online ISSN 2277-1808. 
Analysis of Degraded and Non-Degraded Soils in Irepodun Local Government Area of Kwara State, Nigeria

[20] Senjobi BA, Peluola CO, Senjobi CT, Lawal IO, Ande OT, Salami BT (2010a). Performance of CochorusOlitorius as influenced by soil type and organic manure amendments in Yewa North Local Government Area, Ogun State. Afr. J. Biotechnol. 9(33): 5309-5312.

[21] Chauhan JS. 2001. Fertility status of soils of Birla panchayathsamiti of Jodhpur district (Rajasthan). Msc. (Ag.) Thesis, MPUAT, Udaipur.

Citation: Samuel Alikwe, (2019). "Analysis of Degraded and Non-Degraded Soils in Irepodun Local Government Area of Kwara State, Nigeria” International Journal of Research Studies in Agricultural Sciences (IJRSAS), 5(2), pp. 32-39, http://dx.doi.org/10.20431/2454-6224.0502005

Copyright: (C) 2019 Authors. This is an open-access article distributed under the terms of the Creative Commons Attribution License, which permits unrestricted use, distribution, and reproduction in any medium, provided the original author and source are credited. 